\title{
Developing a Module to Teach Thermodynamics in an Integrated Way to 16 Year Old Pupils
}

\author{
Leen Goovaerts ${ }^{1 *}$, Mieke De Cock ${ }^{2}$, Katrien Struyven ${ }^{3,4}$, Wim Dehaene ${ }^{1}$ \\ ${ }^{1}$ ESAT-MICAS, Faculty of Engineering Science, KU Leuven, BELGIUM \\ ${ }^{2}$ Faculty of Science, Department of Physics and Astronomy, KU Lewven, BELGIUM \\ ${ }^{3}$ Hasselt University, School for Educational Studies, BELGIUM \\ ${ }^{4}$ Vrije Universiteit Brussel, Educational Sciences Department, BELGIUM
}

*Corresponding Author: leen.goovaerts@kuleuven.be

Citation: Goovaerts, L., De Cock, M., Struyven, K. and Dehaene, W. (2019). Developing a Module to Teach Thermodynamics in an Integrated Way to 16 Year Old Pupils. European Journal of STEM Education, 4(1), 02. https:/ / doi.org/10.20897/ ejsteme/3964

Published: April 29, 2019

\begin{abstract}
In order to motivate secondary school pupils for STEM studies and professions, a teaching approach with a focus on integration of STEM components is developed. This paper focuses on the integration of physics and mathematics into an engineering design problem in K10 education, namely building and heating a model of a passive house with a sun boiler. Specific attention is given to the core ideas of integrated STEM while developing this module. These applied ideas comprise problem-centered and cooperative learning, with explicit attention to research and design, as well as taking into account results from discipline specific educational research results.
\end{abstract}

Keywords: thermodynamics, secondary education, problem-based learning

\section{INTRODUCTION}

The current industry in Flanders (Belgium), and in the rest of the Western world, has lack of scientists, technicians and engineers (Van den Berghe and De Martelaere, 2012; Eng, 2014; Act, 2012). The choice for these STEM (Science, Technology, Engineering and Mathematics)-professions is made early in the educational careers of pupils depending on their enthusiasm for and view on these professions. The lack of scientists, technicians and engineers has three reasons. Firstly, current secondary school curricula don't always succeed in showing the content of these jobs, because concepts of different fields are taught in separate courses, while STEM-professions typically rely on integration of concepts from different fields (Eng, 2014). Secondly, the separation of school subjects and the lack of integration between them, makes specific course topics less relevant for pupils (Mehalik et al., 2008). Thirdly, authentic problems are neglected because they require integration of different subjects. Due to this, pupils are not aware of the societal relevance of their course content (Pro, 2014; Sjøberg and Schreiner, 2010; Stuckey et al., 2013). Teaching STEM in an integrated way is put forward as a possible solution to these challenges. This integrated STEM, also named iSTEM, focuses on integration between the different components of STEM. In general, recent research has shown promising results on attitude, motivation and learning outcomes of integrating courses (James et al., 2000; Ross and Hogaboam-Gray, 1998; Lam et al., 2008; Becker and Park, 2011).

Although the number of studies on integrated STEM education is increasing, in depth research on the effect of it is still missing. Moreover, details about the developed learning materials and teaching method are often not described. 
STEM@school is a research project in which a new teaching method for integrated STEM education in secondary school is developed and validated. This includes the design of learning materials that are centered around authentic problems in which the integration of the different S-T-E-M components is made explicit. The framework of this teaching and learning approach is described in Thibaut et al. (2018).

In this paper, one of the designed iSTEM projects in which the central challenge is to build a passive house, heated with a sun boiler, is presented. This iSTEM project is a translation of the iSTEM-framework of Thibaut et al. (2018) in a concrete learning module. First the STEM@school setting and framework is elaborated. Then, the design process itself is described, linking the concrete material to the underlying ideas. Finally, the learning module is described, with explicit attention to the motivation of the choices made and implementation of the discipline specific educational research results.

\section{STEM@SCHOOL}

The described material in this paper is developed in the context of the STEM@school project. The main aim of the project is to develop and validate a learning environment for integrated STEM education in secondary school and as such contribute to the development of research based STEM education.

The project is a collaboration between academic researchers in Science, Engineering, Science education, and Educational sciences on the one hand and secondary school teachers and umbrella organizations on the other hand. This multidisciplinary collaboration ensures the research is relevant for real school practice and the engagement of policy makers increases chances for long term implementation of developed ideas.

The described project team has developed a new teaching approach, with a concrete translation into learning modules. Five central ideas are considered to be essential in the development of the learning materials (Thibaut et al., 2018): integration of different STEM disciplines, problem-centered and cooperative learning, with explicit attention to research and design, as well as the application of discipline specific educational research results. These underlying ideas are explained in detail below.

Since educators recognize the value of pupils understanding the connections and differences between different disciplines (Huntley, 1998; Wicklein and Schell, 1995), and research shows promising results on attitude, motivation and learning outcomes of integrating courses (James et al., 2000; Ross and Hogaboam-Gray, 1998; Lam et al., 2008; Becker and Park, 2011), integration between different disciplines plays a central role in the teaching approach of STEM@school. Nowadays, Christiansen and Rump (2008) indicate that pupils fail to see the connection between mathematics and physics, because physics is rarely mentioned in mathematics class.

A second key concept in the teaching method of STEM@school is the fact that learning should be problemcentered. This approach is adopted to show to pupils that a real problem can seldom be solved by applying ideas from only one discipline, but that a solution requires use and integration of ideas and techniques from different disciplines (Dym et al., 2005). Furthermore, research indicates pupils are more willing to learn when their knowledge is necessary to solve a real-world problem (Dym et al., 2005).

Thirdly, cooperative learning involves pupils working together on an assignment. This cooperation requires active participation of pupils (Is1k and Tarım, 2009). Furthermore, dialogues between pupils during the collaboration take place in the zone of proximal development, which provides a unique learning environment for the pupils (Fosnot and Perry, 1996). Another reason to adopt cooperative learning in the new teaching strategy, is that cooperation is a basic competence for STEM professionals (Dym et al., 2005).

A fourth demand of the STEM@school teaching method, is the fact that pupils engage in doing research and design while solving the problem. Pupils need to be trained in doing all stages of the research and design cycle (Wallin et al., 2016; Mehalik et al., 2008; Dym et al., 2005). This full engagement is important, because when they are only involved in one aspect, pupils will miss the shortfalls of the used method, in the other steps. For example, when pupils are only engaged in data collection, they have no clue of the problems occurring in data analysis. While being actively involved in this process, pupils should realize a fixed path to a solution is a utopia (Banks and Barlex, 2014).

Last but not least, developers of learning material used in STEM@school have added an extra key concept to iSTEM while developing, compared to the framework of Thibaut et al. (2018). Developers need to take discipline specific educational research results into account. In discipline specific educational research, researchers study the teaching and learning of discipline specific ideas, concepts and methods. Ultimately, this results in teaching strategies that support the learning process. Results from this discipline specific educational research are taken into account in the learning module. In this paper, the decisions based on discipline specific educational research are made explicit and explained.

As shown above, literature proves these ideas, problem-centered and cooperative learning, with explicit attention to research and design, as well as taking into account discipline specific educational research results, 
comprise promising learning outcomes, all by themselves. By combining these ideas, the assumption is that maximal learning gain occurs (Mehalik et al., 2008).

Based on the central ideas, different learning modules are developed and implemented in a new course named STEM, in secondary school. In this course, pupils invoke content covered in their other science and mathematic courses. The introduced challenge, which represents the problem, is a stepping stone to the compulsory scientific and mathematical topics. Pupils encounter the challenge in the STEM-course, get stuck and need to combine ideas and concepts that are discussed in different other courses. By applying this approach, pupils are shown the substantive relevance of the different course topics and of science, technology, engineering and mathematics (Ríordáin et al., 2016; Mehalik et al., 2008; Wicklein and Schell, 1995). Furthermore, pupils develop a sophisticated understanding of STEM studies and professions. This facilitates their decision making when choosing a study or profession (Kelley and Knowles, 2016).

STEM@school not only creates an additive course in secondary schools, moreover, a complete integrated STEM-curriculum (Goovaerts et al., 2016) is obtained, as explained below. In this newly developed course, namely the STEM-course, linking with the current science and mathematic courses is crucial (Veretennicoff and Vandewalle, 2015). To create this integrated STEM-curriculum, some requirements need to be fulfilled (Heil et al., 2013). A horizontal alignment of content over the different STEM courses is crucial. This alignment is necessary because two or more disciplines need to be addressed at the same time in order to talk about integrated STEM. When this content is taught just in time, pupils will see the relevance of the content (Ross and Hogaboam-Gray, 1998). On top of that, STEM@school encourages pupils to transfer concepts of one specific discipline to another. Therefore, the concepts need to be abstracted into models and applied in a new context or the other way around, in other words, by forward-reaching-high road transfer or backward-reaching high road transfer (Perkins and Salomon, 1988). Perkins and Salomon (1988) describe forward-reaching-high road transfer 'as one learns something and abstracts it in preparation for applications elsewhere.' On the contrary, when 'one finds oneself in a problem situation, abstracts key characteristics from the situation, and reaches backward into one's experience for matches' is defined as backward-reaching-high road transfer. So, specific attention in the learning modules for abstracting and model thinking, facilitates transfer.

\section{APPROACH TO THE DEVELOPMENT OF AN ISTEM LEARNING ENVIRONMENT}

\section{Design Teams}

Together with teachers, the development team of STEM@school began a brainstorm for developing a new integrated STEM module for the 4th year of Flemish secondary school. This collaboration is a conscious choice of the project team. First of all, teachers have everyday classroom experience with pupils. As a result, they are in the best place to estimate the level of competence of the pupils. In addition, secondary school teachers are familiar with the course content of the curriculum. The development team of the project, on the other hand, has innovative ideas about the teaching approach and course content. Supported by Flanders' educational umbrella organizations, this collaboration provides a broad support base for the newly developed teaching approach.

Some schools in Flanders volunteered for developing learning modules. Each of those schools has composed a team of several teachers, to develop a module in collaboration with researchers. This team is mostly a mixture of undergraduate and graduate teachers, specialized in different courses. This mixture of specialization is necessary because teachers aren't aware of the conceptions of neighboring courses. This awareness is necessary to make explicit connections or differences in meanings of concepts between scientific specialties (Christiansen and Rump, 2008). The mixture of undergraduate and graduate teachers implies other advantages, as described below. An undergraduate teacher is a teacher with a bachelor degree. In this education, future teachers are trained on course content described in the curriculum guidelines and teaching approaches. Furthermore, they are only allowed to teach in the first four years of secondary education. A graduate teacher holds a master degree in a specific discipline and followed a teacher training program afterwards. Sometimes, these teachers first gain industrial working experience before teaching. These teachers can teach from the 3rd until the 6th year of secondary education. A mixture of these types of teachers covers the course content of the whole secondary school and combines different views on teaching.

\section{Content Integration}

In Flemish secondary education, detailed curriculum guidelines apply, and teachers are expected to implement them. This rigid structure makes it almost impossible to change the content of the courses, neither by the teacher, nor by the developers. Given the Flemish curricula for the 3rd and 4th year, an engineering or research project, integrating physics and mathematics, is the most obvious. This integration is limited to these courses due to several reasons. First of all, the link between mathematics and physics is more obvious than other sciences during the $3 \mathrm{rd}$ 


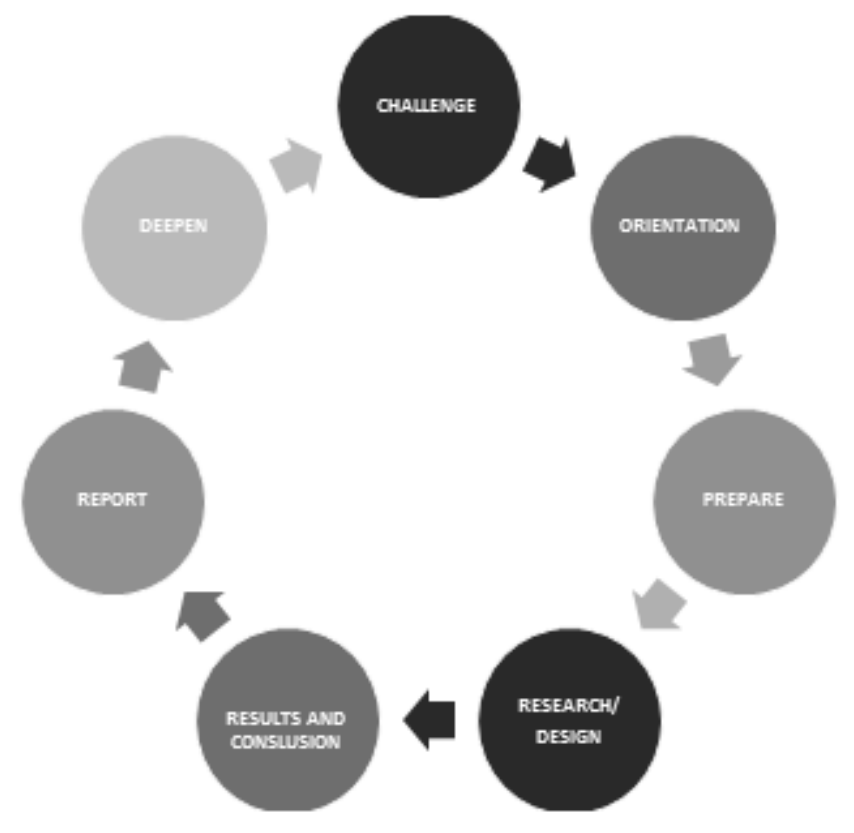

Figure 1. Legacy Cycle

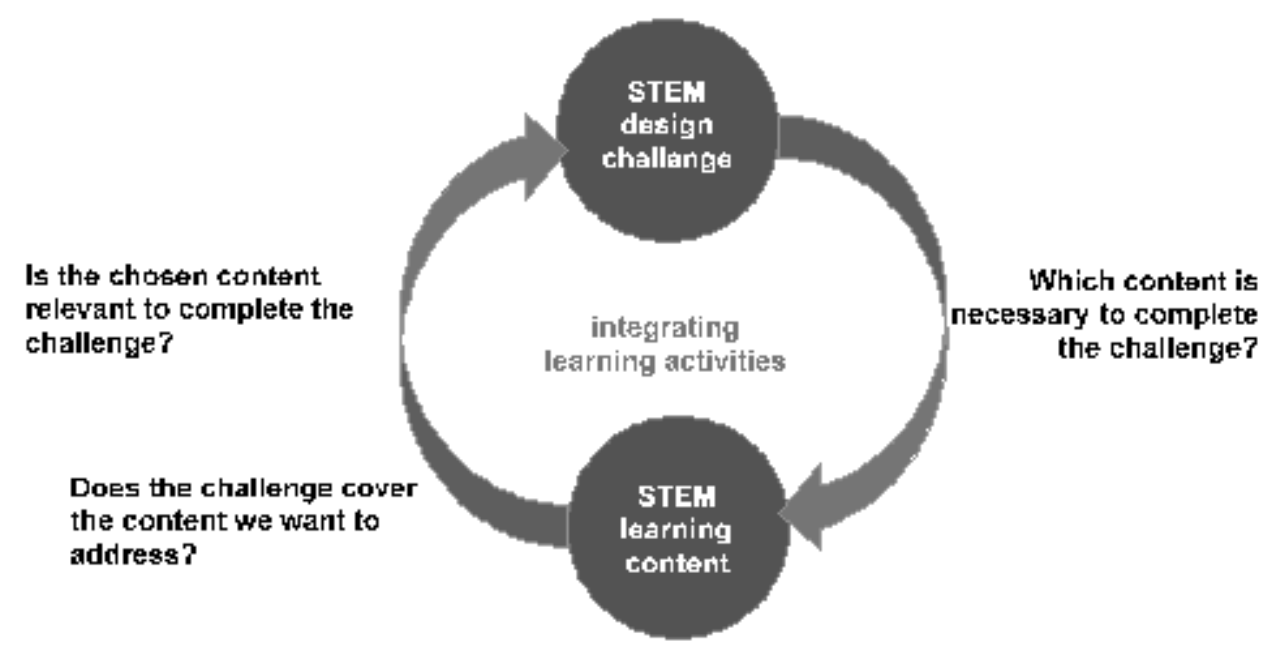

Figure 2. Iterative development process

and 4th year of Flemish secondary school. Secondly, the content of the other sciences in the 3rd and 4th year of Flemish secondary education is less suited to define a project integrating these subjects.

Besides the typical school's content knowledge, the procedural problem solving knowledge is very important for pupils to learn, because the engineering part mostly consists of procedural knowledge in order to solve a problem. In case of STEM@school, pupils should use a design or research cycle. The cycle used is the Legacy Cycle (Klein and Sherwood, 2005), presented in Figure 1. The developers design the modules to force pupils in an implicit way to use the legacy cycle. Pupils should use it in order to solve the engineering or research challenge.

The development process of the learning material is a compact design cycle, as presented in Figure 2. An iterative process needs to be done between the challenge and the learning topics. This iteration needs to assure that the selected content is relevant in completing the challenge. The concerned teachers attach great importance to this iteration, because they think pupils will lose their interest in the STEM-course from the moment that the provided content isn't relevant anymore to the challenge. However, the same teachers are willing to change the challenge in order to integrate some more course content. 


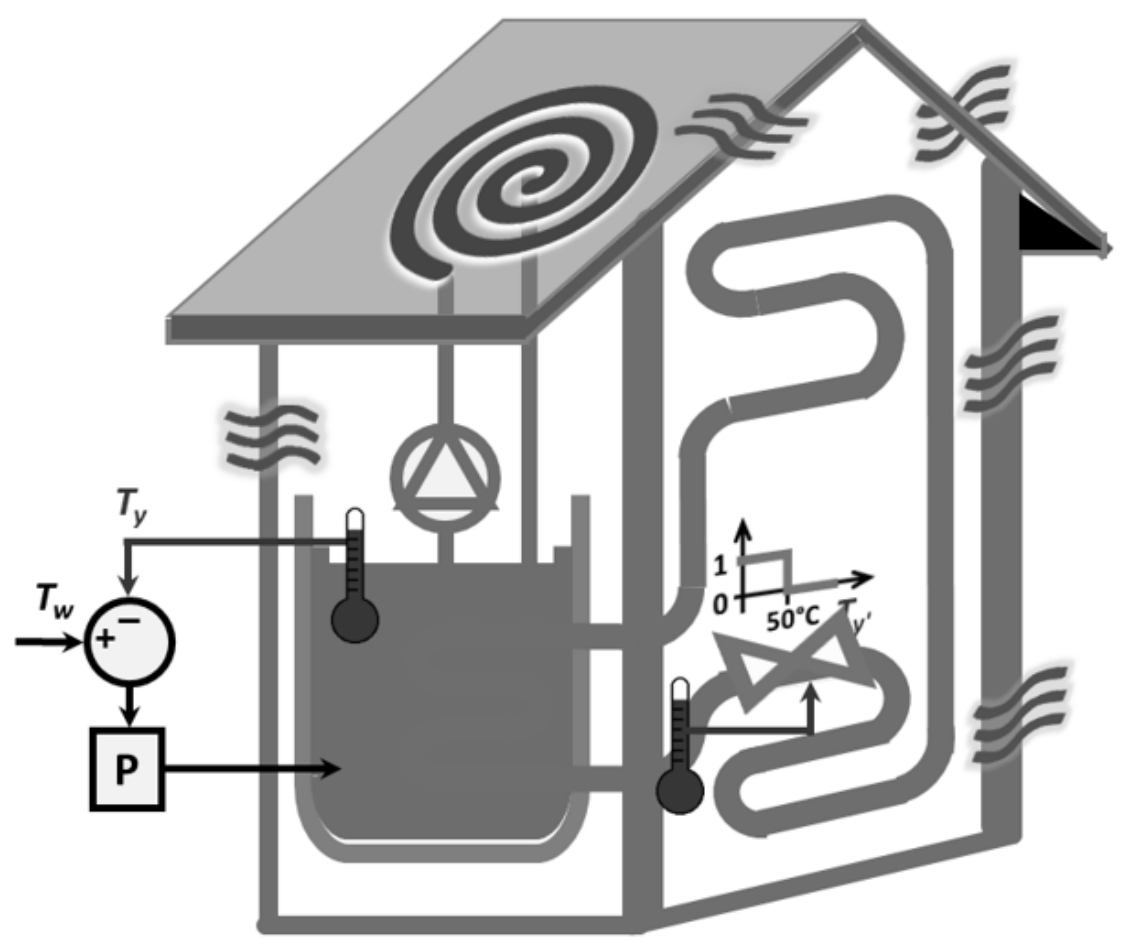

Figure 3. Schematic presentation of the challenge of the passive house

\section{PASSIVE HOUSE AS A CONTEXT}

\section{Challenge}

The physics curriculum for the 4th year of secondary education focuses on three main themes: work, energy and power; pressure and gas laws; and heat. In mathematics, topics related to both geometric and analytic description of the circle, quadratic equations and geometric sequences are dealt with. Taking these curriculum guidelines into account, a project relevant to students and relating to the mentioned content was selected. Finally the challenge was formulated as "Design and develop a model of a passive house with a sun boiler that heats the house and control the temperature in the house". This STEM-design challenge is presented in Figure 3. In this figure a sun boiler is placed on top of the roof. Through a tank, this boiler will provide the hot water for the floor heating of the house. The waves through the walls represent the heat losses to the environment. The loop and graph in the figure illustrate the control system of the house. The description of the control system is beyond the scope of this paper, but is explained in another paper (Goovaerts et al., submitted). The present paper explains how science and mathematics are integrated to design and develop a passive house with a sun boiler.

The choice to formulate a STEM-design challenge about heat, is supported by Papadouris et al. (2008). They claim any teaching approach for energy has to be integrative, in order to expose students to all fundamental aspects of energy as a physical quantity.

\section{Content}

A major argument for the choice of an iSTEM-design challenge on heat and thermodynamics, relates to the learning goals in the established, existing curriculum for the fourth year of physics. According to the prescribed curriculum goals, pupils need to learn about calorimetry. More specifically, they are trained to calculate the temperature rise or added amount of heat during an experiment with a calorimeter. Unfortunately, they don't need to study heat transport. However, every real world heat problem contains heat losses by heat transport, so this content is added to the STEM-course. While treating this concept, pupils learn how to calculate heat losses through the walls and windows of a house.

To relate to the mathematics curriculum, the analytic and geometric approach of the circle is used to build the roof. Pupils are forced to build a roof with a circular support. As a result of this decision, pupils need to formulate the equation of the circle and the tangent to the circle, since the roof is supported by the circle. The intersection 
of the tangent and the circle is the juncture of the roof. This reveals the relevance of the equations of the circle. Other mathematics concepts are necessary while controlling the temperature. Geometric sequences can be used to predict the behavior of the system, since solving differential equations is not yet taught to the pupils. (Goovaerts et al., submitted)

\section{SET UP OF THE LEARNING MATERIALS}

\section{Script}

Once the challenge is formulated, it is split in several submodules. First of all, a sun boiler needs to be build. Secondly, the walls of the house need to be build and insulated. Thirdly, the roof with a circular support needs to be put upon the walls. Finally, the sun boiler needs to be connected with the floor heating of the house and the temperature should be actively controlled. This last part is beyond the scope of this paper, but is described in another paper (Goovaerts et al., submitted).

The first submodule is provided and contains the general storyline, referred to as the script. In this submodule a reference to the other submodules is made, when the content of this submodule is necessary in order to progress in the challenge. This approach results in learning materials of a Babylonian style, with more emphasis to useful models and systems instead of focusing on axioms (Christiansen and Rump, 2008). This Babylonian style focuses on the applicability of the learned knowledge, in contrast to the Euclidian style, in which the focus is on axioms and deductivity. The Babylonian style in only used in the STEM-course, where the developed learning modules are used, since the other course retain their identity, meaning they are taught in a more classic way. The other submodules deal with the building of the sun boiler, the house and controlling the temperature in the house. All submodules contain references to relevant chapters in textbooks. The content of the regular courses is not redeveloped. Consequently, the changes in the regular courses are reduced to a minimum (He et al., 2016).

The script for this challenge contains references to six submodules, as listed below.

(1) The challenge

(2) Energy in a house

(3) The sun boiler

(4) The passive house

(5) Heating the house with the sun boiler

(6) The result

Each submodule is briefly described below, with special attention to the central ideas of STEM@school, namely integration, problem-centered and cooperative learning, research and design learning, and discipline specific educational research input.

\section{Summaries in the Script}

Due to the use of submodules, the total knowledge is fragmented. Therefore, some summaries are embedded in the script to keep pupils on track and select the important issues and formulas. After such a summary, some specific questions about misconceptions are posed. These questions were validated by Yeo and Zadnik (2001) and are proven to be effective in revealing thermodynamic misconceptions by pupils. The teachers are advised to treat these questions in a peer instruction setting (Jasien and Oberem, 2002; Baser, 2006). Together with the concepts, the solutions to these questions are provided for the teacher, with extra explanation. Teachers are also taught, when detecting a misconception, a demonstration or experiment needs to be shown to the pupils and cause a conflict between the student's conception and the newly observed phenomena. Afterwards, a solution needs to be searched in order to solve the misconception (Trumper, 1997; Doménech et al., 2007; Baser, 2006).

\section{The Challenge}

The challenge is described for the pupils in the following way: 'You should build a model of a passive house, heated by a sun boiler and underfloor heating. Being sparingly with energy has become a socially relevant topic. We need to make sure that houses are well insulated and use alternative energy sources.' The challenge presented here resembles a lot to the challenge posed by Schnittka et al. (2010), but in another, more applicable format.

\section{Energy in a House}

In the first step to complete the challenge, pupils need to learn about heat. To make them familiar with the ideas and concepts, pupils study the heat consumption in their own house. After this study, they get more information on renewable energy and the typical problems about energy.

It is important to give pupils insight in the issue of 'shortage of energy'. Pupils should be taught that energy can't be lost, although this is what media write and people say. This results in a misconception by pupils. They 
should learn that energy can be transferred (converted) into other, less useful forms of energy (Doménech et al., 2007; Kaper and Goedhart, 2002) and as such is lost for further use. This misconception is already treated in the first two years of secondary education, so pupils only need to be reminded for that.

\section{The Sun Boiler}

After the exploration phase, it is time to work on the challenge itself. As the challenge describes, a sun boiler needs to be built. In this submodule and in parallel with the physics course, pupils learn about heat capacity and thermal equilibrium, which are crucial aspects in learning thermodynamics (Carlton, 2000; Arnold and Millar, 1996). These concepts are best explained by the kinematic molecular theory (Wiser and Amin, 2001; Carlton, 2000). When using these concepts in order to explain heat capacity, the transfer to upcoming concepts as latent heat, will be much easier.

An analogy is used to make pupils confident with the concept of thermal equilibrium. Arnold and Millar (1996) described an analogy with water flow. Pupils are demonstrated a glass of water with an inflow and an outflow. Next, they are asked how to adapt the flows in order to keep the water level constant, raise or decrease. The water level then becomes the equivalent of the thermal equilibrium, which makes clear that the net flow needs to be zero in order to be in balance.

Once the pupils master the concept of heat capacity, they can use this to select the best material to build a sun boiler. Therefore, pupils conduct some experiments. Giving enough freedom during the experiments, makes them feel more satisfied and important making the decisions. So more open-ended experiments are recommended. (Berg et al., 2003). This freedom can be practiced in different gradients. The most freedom is given when pupils are asked to design a set of experiments in order to choose the best materials to build a sun boiler. An intermediate form is to discuss with them which experiments need to be set up, but let them design the experiments themselves. The minimum amount of freedom that is still acceptable is given when the experiments with the different steps are given to the pupils, but the pupils are free to choose the amount of the concerned materials. In the latter, pupils are forced to think about the constants, parameters, dependent and independent variables. As a result, the experiments will not become a simple cooking book experiment. As mentioned before, the more freedom pupils get, the more ownership they gain of the experiment. Though, because of boundary conditions, it is not always possible to give so much freedom to the pupils. The amount of time devoted to the STEM-course is limited and since freedom asks a lot of extra time, freedom can be restricted. Another reason to limit the freedom of pupils, is that the materials available in the school are below par. In the module different stages of freedom are presented to the teachers.

The necessary experiments provide an ideal climate to force pupils to interpret graphs in a physical context. Research has demonstrated pupils feel unconfident and unable to do this, because they have troubles in making a connection between a graphical representation and the physical process it represents (Jasien and Oberem, 2002; Boohan et al., 2001). In this context for example, pupils need to measure the temperature over time of three equal reservoirs, only their colors differ. The pupils are asked to put these data into a graph and select the most appropriate color. Consequently, they have to use their mathematical knowledge about graphs and slopes in order to make a physical conclusion.

In a final stage, the efficiency of the sun boiler needs to be calculated. It's important to check how much power is necessary to reach a certain amount of heat in the water, especially in the current debates on alternative energy. Moreover, proving and improving efficiency is a daily goal of an engineer. Since pupils have to solve an engineering challenge, efficiency will always be a part of it. Besides the social relevance of efficiency, it is part of the curriculum goals, imposed by the government and therefore important to include in the project.

\section{The Passive House}

Besides the sun boiler, a model of a passive house needs to be made. The first step is to build a house, the second step is to make the house as passive as possible. In order to build the house, pupils receive the dimensions of the rectangular house. These dimensions are important, because the scaling factor relative to a real house needs to be correct, otherwise it is impossible to heat the house with the floor heating. When pupils received the dimensions, they go to work to design the floor and the walls. To design the roof, they need extra mathematical knowledge. The roof is a triangle, supported by half a circle. Hence, pupils have to calculate the characteristics of the circle, such as the radius and the points of tangency with the roof. This calculations can be done using an analytical or geometric approach, depending on the knowledge of the pupils and the curriculum guidelines. This step needs to be done before building the house itself, because the different parts of the house are laser cut, so the design has to be correct from the beginning. It is important to integrate mathematical calculations in the design process, so pupils are aware that the design process has a scientific ground.

Next, the house needs to be insulated to obtain a passive house. To obtain a relevant insulation and the necessary calculations, knowledge about heat transport is required. Pupils are first given a brief introduction about 
the different types of heat transport, such as conduction, convection and radiation. To make sure pupils can distinguish these types of heat transport, some everyday life situations are discussed. The presented examples are already researched and found useful for pupils of secondary school. For example, the thermos is designed in order to obstruct multiple forms of heat transport (Lewis and Linn, 2003).

The following lessons focus on heat conduction, because it is the most important form of heat transport when insulating houses. The concept of the heat conduction coefficient is explained and linked to the terms insulator and conductor. To clarify to pupils that a material will never be an ideal insulator or conductor, various materials are presented at a continuum (Lewis and Linn, 2003). Various conceptual questions are posed to the pupils, in order to eliminate misconceptions. A frequently appearing misconception is that two or more objects are at a different temperature, because they don't feel as equally hot, although they are in the same room. This idea typically leads to the misconception that metals are naturally colder than non-metals (Schnittka and Bell, 2011; Frederik et al., 1999; Carlton, 2000; Sözbilir, 2003; Lewis and Linn, 2003). Some examples are discussed during the course in order to clarify to pupils that a conductor always feels colder than an insulator although they are at the same temperature, because a conductor immediately conducts the heat of the body (Lewis and Linn, 2003). Another addressed misconception is that insulators keep cold out (Schnittka and Bell, 2011). Pupils should be aware of the fact that insulators obstruct the natural flow of heat, from the hot places to the cold places. This misconception is addressed by letting pupils think about the temperature inside the house during hot summer days in comparison with cold winter days.

In this phase, pupils are able to calculate the heat loss through the walls and windows of the house. The next step is to investigate whether the chosen insulation material will be good enough. The losses to the outside depend on the temperature of the inside. The temperature of the inside raises according to the heating time. At a certain point, the heat losses will be equal to the power to warm the house, consequently the equilibrium temperature is reached (Arnold and Millar, 1996). And this equilibrium temperature should be a lot higher than the desired temperature, because otherwise it is impossible to reach the desired temperature. This whole process of the equilibrium temperature can be explained with the same analogy used to explain thermal equilibrium (Arnold and Millar, 1996), mentioned before.

\section{Heating the House}

Of course, it is important to assure that the house can be heated with the sun boiler and the temperature can be set. First pupils should learn how to control the temperature in the house. Therefore, some basic knowledge about control engineering is necessary. How this should be handled for pupils is described in another paper (Goovaerts et al., submitted). To make the control process easier, pupils can start by using a power resistor. In this case, the power put in the house is invariable, which is easier to calculate.

The end goal is to heat the house with the heated water of the sun boiler. To reach this goal, pupils should build a floor heating system in the house. With the length of the floor heating and the dimensions of the sun boiler, pupils can calculate if it's possible to reach the desired temperature and how long it takes for the house to heat up. Though, a few simplifications are necessary in order to facilitate pupils to make these calculations. The first assumption clarifies that the temperature of the water in the floor system is the same at all places in the system. The conducted heat only lowers the temperature when the used fluid leaves the tubes in the floor. Since the temperature in a realistic situation would vary over time and place, a tough integral and differential equation would need to be solved. Because this is far above the heads of 16-year old pupils, the mentioned simplification is necessary. Another assumption is that the temperature in the house stays at the begin temperature until enough heat is provided to reach the desired temperature. The transient response of the heating system itself is ignored.

\section{The Result}

When all previous steps are completed, the sun boiler can be connected and the house should be heated with the sun boiler. Now, pupils need to reflect on the task. It is time to catalogue what went good, what went wrong, how the design can be adapted in order to improve the efficiency of the sun boiler or the heating of the house,... Pupils now finally see the whole solution of their initial challenge. Pupils feel proud to have completed the challenge.

Also a check with governmental rules about heat energy and heat losses in houses is done. As a conclusion, this learning module has covered all curriculum guidelines concerning heat. The experimental approach requires more time investment, but involves a deeper learning of the concepts, with less misconceptions.

\section{IMPLEMENTATION OF THE LEARNING MODULE IN THE CLASSROOM}

The presented learning module is tested a first time in 30 schools in Flanders. Through meetings with the teachers and questionnaires, feedback is collected. 
Teachers mentioned an increase in motivation for learning the concepts of heat and doing the experiments. According to the teachers, this is owing to the context in which pupils need to complete the experiments in order to complete the proposed challenge. Moreover, teachers claimed pupils have a better view on the concept of heat because of the conducted study in their own house.

Although most teachers don't study results of discipline specific educational research themselves, they reported they have worked explicitly on the presented misconceptions in the module.

Unfortunately, building the passive house as well as the sun boiler seemed to be too time consuming, so teachers needed to make choices. Some teachers decided to build the house this year and the sun boiler next year, or the other way around. Others opted to split the class and let half the class make the house and the other half the sun boiler.

\section{CONCLUSION}

A new approach to teach concepts related to heat and heat transport in secondary school is described, which integrates physics and mathematics in an engineering design problem, taking into account results from discipline specific educational research. While solving this engineering design challenge, pupils become aware of the necessity of integrating science, mathematics and technology. Furthermore, every design team will follow its own path in solving the challenge, yet led by a research or design cycle. Thus, they feel free and in charge. Being a real world problem to solve, pupils are able to contact experts, link it to the news and compare their solution to the existing ones.

An advantage of this approach is that pupils immediately grasp the relevance of subject matter provided in separate STEM courses, which increases their motivation. Moreover, we expect pupils to gain a deeper level of understanding the content knowledge because of the relevance and specific attention to certain parts. This increased motivation, knowledge and awareness makes sure, pupils can make a more motivated choice regarding their future studies and profession.

\section{ACKNOWLEDGEMENTS}

The work described in this paper is founded by Flemish government under the IWT-SBO project STEM@school.

Special thank you to Jolien De Meester for illustrating this engineering design challenge.

Thanks to my colleagues in this project, Stijn Ceuppens, Jolien De Meester and Lieve Thibaut, for the discussions about the content and teaching approach.

\section{CONFLICT OF INTEREST}

On behalf of all authors, the corresponding author states that there is no conflict of interest.

\section{REFERENCES}

(2012). Actieplan voor het stimuleren van loopbanen in wiskunde, exact wetenschappen en techniek. Technical report, Vlaamse overheid. 14

(2014). Engineering UK 2014 The state of engineering. Engineering UK.

(2014). Project STEM: Book of insights. Mindshare.

Arnold, M. and Millar, R. (1996). Learning the scientific story: A case study in the teaching and learning of elementary thermodynamics. Science education, 80(3), 249-281. https://doi.org/10.1002/(SICI)1098237X(199606)80:3<249::AID-SCE1>3.0.CO;2-E

Banks, F. and Barlex, D. (2014). Teaching STEM in the secondary school: Helping teachers meet the challenge. Routledge. https:// doi.org/10.4324/9780203809921

Baser, M. (2006). Fostering conceptual change by cognitive conflict based instruction on students understanding of heat and temperature concepts. Eurasia Journal of Mathematics, Science and Technology Education, 2(2), 96-114. https://doi.org/10.12973/ ejmste/75458

Becker, K. and Park, K. (2011). Effects of integrative approaches among science, technology, engineering, and mathematics (stem) subjects on students' learning: A preliminary meta-analysis. Journal of STEM Education: Innovations and Research, 12(5/6), 23. 
Berg, C. A. R., Bergendahl, V. C. B., Lundberg, B. and Tibell, L. (2003). Benefiting from an open-ended experiment? A comparison of attitudes to, and outcomes of, an expository versus an open-inquiry version of the same experiment. International Journal of Science Education, 25(3), 351- 372. https://doi.org/10.1080/09500690210145738

Boohan, R., Stylianidou, F. and Ogborn, J. (2001). Teaching about energy and training for innovation. Physics Teacher Education Beyond 2000, 177-180.

Carlton, K. (2000). Teaching about heat and temperature. Physics Education, 35(2), 101. https://doi.org/10.1088/0031-9120/35/2/304

Christiansen, F. V. and Rump, C. (2008). Three conceptions of thermodynamics: Technical matrices in science and engineering. Research in Science Education, 38(5), 545-564. https://doi.org/10.1007/s11165-007-9061-x

Doménech, J. L., Gil-Pérez, D., Gras-Martí, A., Guisasola, J., Martínez-Torregrosa, J., Salinas, J., Trumper, R., Valdés, P. and Vilches, A. (2007). Teaching of energy issues: A debate proposal for a global reorientation. Science \& Education, 16(1), 43-64. https:// doi.org/10.1007/s11191-005-5036-3

Dym, C. L., Agogino, A. M., Eris, O., Frey, D. D. and Leifer, L. J. (2005). Engineering design thinking, teaching and learning. Journal of Engineering Education, 94(1), 103-120. https://doi.org/10.1002/j.21689830.2005.tb00832.x

Fosnot, C. T. and Perry, R. S. (1996). Constructivism: A psychological theory of learning. Constructivism: Theory, perspectives and practice, 2, 8-33.

Frederik, I., Der Valk, T. V., Leite, L. and Thorén, I. (1999). Pre-service physics teachers and conceptual difficulties on temperature and heat. European Journal of Teacher Education, 22(1), 61-74. https://doi.org/10.1080/0261976990220105

Goovaerts, L., De Cock, M. and Dehaene, W. (2016). Assessment of stem-design challenges: review and design. Wroclaw.

Goovaerts, L., De Cock, M., Struyven, K. and Dehaene, W. A concrete proposal to introduce control theory to 16 year old pupils. Submitted.

He, Q. P., Wang, J., Zhang, R., Johnson, D., Knight, A. and Polala, R. (2016). A modular approach to integrating biofuels education into chemical engineering curriculum: Part I-learning materials. Chemical Engineering Education, 50(2), 98-106.

Heil, D., Pearson, G. and Burger, S. (2013). Understanding integrated stem education: Report on a national study. Atlanta. American Society for Engineering Education.

Huntley, M. A. (1998). Design and implementation of a framework for defining integrated mathematics and science education. School Science and Mathematics, 98(6), 320-327. https://doi.org/10.1111/j.1949-8594.1998.tb17427.x

Isık, D. and Tarım, K. (2009). The effects of the cooperative learning method supported by multiple intelligence theory on Turkish elementary students mathematics achievement. Asia Pacific Education Review, 10(4), 465. https:// doi.org/10.1007/s12564-009-9049-5

James, R. K., Lamb, C. E., Householder, D. L. and Bailey, M. A. (2000). Integrating science, mathematics and technology in middle school technology-rich environments: A study of implementation and change. School Science and Mathematics, 100(1), 27-35. https://doi.org/10.1111/j.1949-8594.2000.tb17317.x

Jasien, P. G. and Oberem, G. E. (2002). Understanding of elementary concepts in heat and temperature among college students and k-12 teachers. J. Chem. Educ., 79(7), 889. https:// doi.org/10.1021/ed079p889

Kaper, W. H. and Goedhart, M. J. (2002). 'Forms of energy', an intermediary language on the road to thermodynamics? Part I. International Journal of Science Education, 24(1), 81-95. https:// doi.org/10.1080/09500690110049114

Kelley, T. R. and Knowles, J. G. (2016). A conceptual framework for integrated stem education. International Joumal of STEM Education, 3(1), 1-11. https:// doi.org/10.1186/s40594-016-0046-z

Klein, S. S. and Sherwood, R. D. (2005). Biomedical engineering and cognitive science as the basis for secondary science curriculum development: a three year study. School Science and Mathematics, 105(8), 384-401. https://doi.org/10.1111/j.1949-8594.2005.tb18059.x

Lam, P., Doverspike, D., Zhao, J., Zhe, J. and Menzemer, C. (2008). An evaluation of a stem program for middle school students on learning disability related ieps. Journal of STEM Education: Innovations and Research, 9(1/2), 21.

Lewis, E. L. and Linn, M. C. (2003). Heat energy and temperature concepts of adolescents, adults and experts: Implications for curricular improvements. Journal of Research in Science Teaching, 40, S155- S175.

Mehalik, M. M., Doppelt, Y. and Schuun, C. D. (2008). Middle-school science through design-based learning versus scripted inquiry: Better overall science concept learning and equity gap reduction. Journal of Engineering Education, 97(1), 71-85. https://doi.org/10.1002/j.2168-9830.2008.tb00955.x

Papadouris, N., Constantinou, C. P. and Kyratsi, T. (2008). Students' use of the energy model to account for changes in physical systems. Journal of Research in science teaching, 45(4), 444-469. https://doi.org/10.1002/tea.20235

Perkins, D. N. and Salomon, G. (1988). Teaching for transfer. Educational leadership, 46(1), 22-32. 
Ríordáin, M. N., Johnston, J. and Walshe, G. (2016). Making mathematics and science integration happen: key aspects of practice. International Journal of Mathematical Education in Science and Technology, 47(2), $233-255$. https:/ / doi.org/10.1080/0020739X.2015.1078001

Ross, J. A. and Hogaboam-Gray, A. (1998). Integrating mathematics, science and technology: effects on students. International Journal of Science Education, 20(9), 1119-1135. https:/ / doi.org/10.1080/0950069980200908

Schnittka, C. and Bell, R. (2011). Engineering design and conceptual change in science: Addressing thermal energy and heat transfer in eighth grade. International Journal of Science Education, 33(13), 1861- 1887.

Schnittka, C., Bell, R. and Richards, L. (2010). Save the penguins: Teaching the science of heat transfer through engineering design. Science Scope, 34 (3), 82-91. https://doi.org/10.1080/09500693.2010.529177

Sjøberg, S. and Schreiner, C. (2010). The rose project: An overview and key findings. Oslo: University of Oslo, pages 131.

Sözbilir, M. (2003). A review of selected literature on students misconceptions of heat and temperature. Bogaziçi University Journal of Education, 20(1), 25-41.

Stuckey, M., Hofstein, A., Mamlok-Naaman, R. and Eilks, I. (2013). The meaning of relevancein science education and its implications for the science curriculum. Studies in Science Education, 49(1), 1-34. https://doi.org/10.1080/03057267.2013.802463

Thibaut, L., Ceuppens, S., De Loof, H., De Meester, J., Goovaerts, L., Struyf, A., ..., others. (2018). Integrated stem education: A systematic review of instructional practices in secondary education. European Journal of STEM Education. https://doi.org/10.20897/ejsteme/85525

Trumper, R. (1997). Applying conceptual conflict strategies in the learning of the energy concept. Research in Science \& Technological Education, 15(1), 5-18. https:/ / doi.org/10.1080/0263514970150101

Van den Berghe, W. and De Martelaere, D. (2012). Kiezen voor stem. De keuze van jongeren voor technische en wetenschappelijke studies., VRWI studiereeks, Brussel, (25), 18-22.

Veretennicoff, I. and Vandewalle, J. (2015). De STEM-leerkracht. Brussel: KVAB Press.

Wallin, P., Adawi, T. and Gold, J. (2016). Linking teaching and research in an undergraduate course and exploring student learning experiences. European Journal of Engineering Education, 1-17.

Wicklein, R. C. and Schell, J. W. (1995). Case studies of multidisciplinary approaches to integrating mathematics, science, \& technology education.

Wiser, M. and Amin, T. (2001). Is heat hot? Inducing conceptual change by integrating everyday and scientific perspectives on thermal phenomena. Learning and Instruction, 11(4), 331-355. https://doi.org/10.1016/S09594752(00)00036-0

Yeo, S. and Zadnik, M. (2001). Introductory thermal concept evaluation: Assessing students' understanding. The Physics Teacher, 39(8), 496-504. https://doi.org/10.1119/1.1424603 